\title{
Hydroxychloroquine: A Physiologically-Based Pharmacokinetic Model in the Context of Cancer-Related Autophagy Modulation $\$$
}

\author{
Keagan P. Collins, Kristen M. Jackson, and Daniel L. Gustafson \\ School of Biomedical Engineering (K.P.C., K.M.J., D.L.G.) and Department of Clinical Sciences (D.L.G.), Colorado State \\ University, Fort Collins, Colorado; and University of Colorado Cancer Center, Aurora, Colorado (D.L.G.)
}

Received October 10, 2017; accepted February 6, 2018

\begin{abstract}
Hydroxychloroquine (HCQ) is a lysosomotropic autophagy inhibitor being used in over 50 clinical trials either alone or in combination with chemotherapy. Pharmacokinetic $(\mathrm{PK})$ and pharmacodynamic (PD) studies with HCQ have shown that drug exposure in the blood does not correlate with autophagy inhibition in either peripheral blood mononuclear cells or tumor tissue. To better explain this PK/PD disconnect, a PBPK was developed for HCQ describing the tissue-specific absorption, distribution, metabolism, and excretion as well as lysosomespecific sequestration. Using physiologic and biochemical parameters derived from literature or obtained experimentally, the model was first developed and validated in mice, and then
\end{abstract}

adapted to simulate human HCQ exposure in whole blood and urine through allometric scaling and species-specific parameter modification. The human model accurately simulated average steady-state concentrations (Css) of those observed in five different $\mathrm{HCQ}$ combination clinical trials across seven different doses, which was then expanded by comparison of the Css distribution in a virtual human population at this range of doses. Value of this model lies in its ability to simulate HCQ PK in patients while accounting for PK modification by combination treatment modalities, drug concentrations at the active site in the lysosome under varying $\mathrm{pH}$ conditions, and exposure in tissues where toxicity is observed.

\section{Introduction}

Hydroxychloroquine (HCQ) is a 4-aminoquinoline class molecule traditionally used as an antimalarial medication, but currently being investigated in over 50 cancer clinical trials either alone or in combination with chemotherapy (ClinicalTrials.gov). HCQ's putative mechanism of anticancer activity is through the inhibition of autophagy, a naturally occurring metabolic process that involves the digestion of a cell's own organelles, proteins, and other cellular debris in the lysosome. HCQ is the current gold standard for autophagy inhibition in a clinical setting as it exhibits similar potency yet less toxicity in long-term dosing compared with other clinically approved autophagy inhibitors, such as chloroquine (Shi et al., 2017). There is significant evidence that autophagy is

This work was supported by National Institutes of Health National Cancer Institute [Grant R01CA190170 Therapeutic Targeting of AutophagyDependent Cancer] and by Department of Defense Congressionally Directed Medical Research Program (CDRMP) Breast Cancer Research Program [Grant BC130103P1 Identifying and Targeting Autophagy Dependence to Eliminate Metastatic Breast Cancer]. Support for animal studies was provided by the University of Colorado Cancer Center Pharmacology Shared Resource and the associated Cancer Center Support [Grant P30CA046934].

Part of this work was presented as follows: Collins KP, Jackson KM, and Gustafson DL (2017) A physiologically-based pharmacokinetic (PBPK) model of hydroxychloroquine [1503]. American Association of Cancer Research 77 (Suppl 13)

https://doi.org/10.1124/jpet.117.245639.

S This article has supplemental material available at jpet.aspetjournals.org. heavily upregulated in certain tumor types, acting as a survival mechanism against both the harsh tumor environment and chemotherapy treatments (Yang et al., 2011; Levy et al., 2017). Inhibition of this process by augmenting the primary treatment method with HCQ has been shown to resensitize tumors to a resistant therapy regimen or enhance response to a current treatment regimen (Amaravadi et al., 2011; Carew et al., 2012; Barnard et al., 2014; Levy et al., 2014).

Mechanistically, HCQ is a weakly basic compound that alkalinizes the highly acidic lysosome, preventing the autophagosome-lysosome fusion step of autophagy (de Duve, 1983; Lu et al., 2017a). This mechanism drives its pharmacokinetics (PK), primarily through an ion-trap accumulation observed in lysosomes and other acidic compartments. Overall, HCQ PK has been well characterized in multiple species, and the PK profile appears to scale linearly with dose escalation, though exhibits a significant amount of intersubject variability (McChesney, 1983; Tett et al., 1988; Furst, 1996; Lim et al., 2009; Fan et al., 2015). Sources of variability are likely due to the fact that these studies have been done by different research groups over the course of decades as well as variance in absorption, distribution, metabolism, and elimination (ADME) factors related to the physicochemical properties that drive its PK.

HCQ is typically administered as an oral tablet, in doses ranging from 100 to $1200 \mathrm{mg}$ daily, by which it is readily

ABBREVIATIONS: ADME, absorption, distribution, metabolism, and elimination; AUC, area under the curve; Css, steady-state concentration; $\mathrm{dHCQ}$, desethyl-hydroxychloroquine; GFR, glomerular filtration rate; HCQ, hydroxychloroquine; MAPE\%, median absolute performance error; MPE $\%$, median performance error; NCA, noncompartmental analysis; PBPK, physiologically-based pharmacokinetic modeling; PD, pharmacodynamics; PE, performance error; PK, pharmacokinetics; $t_{1 / 2}$, half-life. 
absorbed within 2-4 hours (Browning, 2014). The fraction absorbed is estimated to be $74 \% \pm 13 \%$ (Tett et al., 1989; Browning, 2014). HCQ blood concentration peaks shortly after the absorption phase and falls relatively quickly due to rapid partitioning into organs. Accumulation in lysosomes appears to drive the large volume of distribution in plasma, whereas binding to melanin contributes to the long terminal half-life $\left(t_{1 / 2}\right)$ (Tett et al., 1990). It is approximately $50 \%$ bound to plasma protein in the blood (Furst, 1996). Metabolism appears to be the primary driver of HCQ clearance. It occurs in the liver through CYP3A4- and CYP2C3-driven dealkylation to form desethylhydroxychloroquine, desethylchloroquine, and bisdesethylchloroquine, the former that exhibits therapeutic activity and PK thought to be comparable to HCQ (McChesney et al., 1966; Kim et al., 2003; Browning, 2014; Qu et al., 2015). Rate of metabolism varies tremendously across species, leading to significant cross-species differences in $t_{1 / 2}$ that ranges from hours in mice to days in humans (Tett et al., 1988). Excretion takes place primarily in the kidneys, accounting for about $22 \%$ of HCQ total blood clearance, with liver clearance assumed to account for the rest (Tett et al., 1988). Mean renal clearance from plasma is reported as three to four times greater than glomerular filtration rate (GFR) corrected for protein binding, suggesting the drug is secreted in addition to filtration (Tett et al., 1988).

In the context of cancer treatment, HCQ blood exposure correlates with neither tumor exposure nor pharmacodynamic (PD) markers of autophagy inhibition in both peripheral blood mononuclear cells and tumor tissue (Barnard et al., 2014). To investigate the PK/PK and PK/PD disconnect observed in HCQ treatment, as well as the high interindividual patient variability in PK studies, a physiologically-based pharmacokinetic model (PBPK) serves as a powerful investigative tool. This model allows for simulation of patient profiles and study of relationships between drivers. Developed around key tissues as well as physiologic and biochemical properties associated with the ADME profile, this PBPK model of HCQ can simulate exposure in tissues associated with toxicity as well as therapeutic effect. It can also investigate the variability in tumor $\mathrm{pH}$ that may contribute to the disconnect between exposure in the blood and autophagy inhibition in the tumor, specifically the inverse relationship between HCQ uptake and extracellular $\mathrm{pH}$ (Pellegrini et al., 2014).

The PBPK model described for HCQ (Fig. 1) was developed using biochemical and physiologic parameters adapted from literature or obtained experimentally, with significant focus on the $\mathrm{pH}$-based aspect of PK. Tissues represented in the model are involved with absorption, metabolism, excretion, and binding, or are subject to toxicity. Model output simulates single i.p. dose tissue exposure in mice. Biochemical and physiologic parameters were then adjusted accordingly to simulate whole-blood exposure in humans. Simulation output across multiple dosing regimens and across different species matches well with experimental PK data, indicating that key drivers of HCQ PK are accounted for by the PBPK model.

\section{Materials and Methods}

\section{PK Study in Mice}

Protocols for the mouse studies were approved by the Institutional Animal Care and Use Committee at Colorado State University.
Female BALB/c mice were treated with a single i.p. of 20,40 , or 80 mg/kg HCQ (H0915; Sigma-Aldrich, St. Louis, MO). Tissues and whole blood were collected from three mice for each dose at 3, 6, 12, 24,48 , and 72 hours $(n=54)$. Levels of HCQ and desethylhydroxychloroquine (dHCQ) in whole blood and tissues were determined via a previously validated liquid chromatography-tandem mass spectrometry assay (Barnard et al., 2014). Briefly, $100 \mu \mathrm{l}$ tissue homogenate was added to a microcentrifuge tube along with $10 \mu \mathrm{l}$ Milli-Q water, $10 \mu \mathrm{l}$ 50/50 acetonitrile/Milli-Q, $10 \mu \mathrm{l} 2.5 \mu \mathrm{g} / \mathrm{ml}$ CQ (internal standard), and $100 \mu \mathrm{l}$ acetonitrile. Samples were vortexed for 5 minutes and centrifuged for 10 minutes at 13,300 rpm. Eighty microliters of this mix was transferred to an autosampler vial and mixed with $120 \mu \mathrm{l}$ Milli-Q water prior to mass spectrometer analysis. Standards and quality controls were prepared in an identical manner. Data points below the LLOQ of $1 \mathrm{ng} / \mathrm{ml}$ for HCQ and $10 \mathrm{ng} / \mathrm{ml}$ for dHCQ were excluded. Noncompartmental analysis (NCA) measured exposure, as determined by area under the drug concentration versus time curve $\left(\mathrm{AUC}_{0-\mathrm{inf}}\right)$, to both $\mathrm{HCQ}$ and $\mathrm{dHCQ}$.

\section{HCQ Microsomal Metabolism Studies}

Metabolism rate constants for the human PBPK model were obtained through microsomal incubation. Pooled mixed gender human liver microsomes at $20 \mathrm{mg} / \mathrm{ml}$ were obtained from XenoTech (Kansas City, $\mathrm{KS}$ ) and were split into $100 \mu \mathrm{l}$ aliquots prior to beginning microsomal incubations. Briefly, microsome stocks were diluted to $0.5 \mathrm{mg} / \mathrm{ml}$ in $100 \mathrm{mM}$ phosphate buffer and preincubated with a NADPHregenerating system for 5 minutes. The $100 \times$ HCQ (H0915; SigmaAldrich) was spiked into the microsome mix and incubated for up to 3 hours. Reactions were terminated by addition of $100 \mu \mathrm{l}$ acetonitrile, vortexed for 5 minutes, and centrifuged at 14,000 rpm for 5 minutes to pellet the microsomal protein. Prior to analysis by high-pressure liquid chromatography, the samples were mixed 50:50 with the internal standard of $500 \mathrm{ng} / \mathrm{ml}$ camptothecin dissolved in MilliQ water. Rate of metabolism was determined by rate of $n$-desethylhydroxychloroquine formation, the primary metabolite of HCQ (Browning, 2014). Analysis of samples was done using the liquid chromatography-tandem mass spectrometry assay mentioned in the previous section. Standards and quality control samples were prepared in an inactive microsomal homogenate matrix in the same way as samples and containing identical amounts of internal standard.

\section{Lysosomal Quantification in Mouse Tissue}

Lysosome contents of the various tissues incorporated in the model were determined by analyzing acid phosphatase enzyme activity. It was assumed that lysosome volume fraction of the tissue was directly

\section{Hydroxychloroquine (HCQ)}

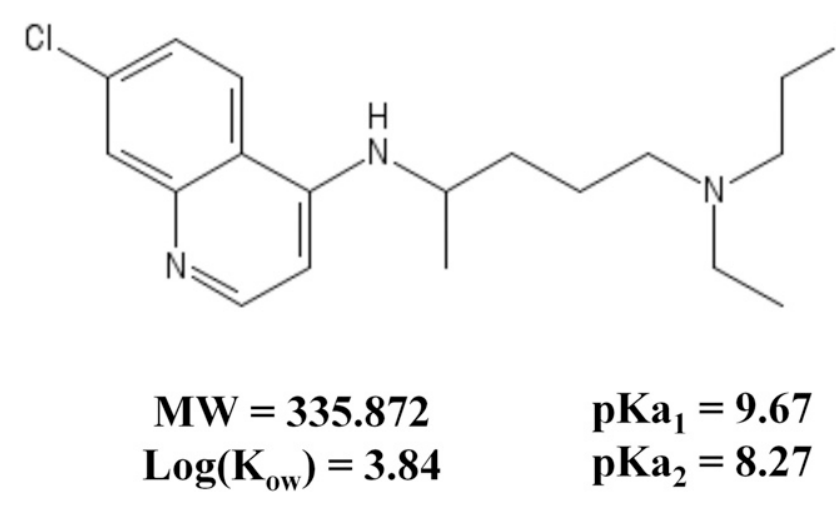

Fig. 1. HCQ molecular structure with key physicochemical properties. 
proportional to the acid phosphatase activity in that tissue. Tissues were extracted from BALB/c mice, diluted to $100 \mathrm{mg} / \mathrm{ml}$ in $0.2 \mathrm{M}$ acetic acid buffer $(\mathrm{pH}=5.0)$, and homogenized in a Bullet Blender Storm 2400 at max speed for 5 minutes. Samples were centrifuged at $5000 \mathrm{rpm}$ for 10 minutes at $4^{\circ} \mathrm{C}$, and homogenate was collected and transferred to new tubes. Homogenate was vortexed, and $150 \mu \mathrm{l}$ was transferred to a cuvette, followed by $600 \mu \mathrm{l}$ acetic acid buffer to this same cuvette. The cuvette was then incubated at $37^{\circ} \mathrm{C}$ for 10 minutes to inactivate additional enzymes. After incubation, $250 \mu \mathrm{l} 32 \mathrm{mM}$ p-nitrophenol dissolved in water was added to the cuvette. Cuvette was inverted and read immediately on a DU 800 spectrophotometer at $420 \mathrm{~nm}$ for 5 minutes to collect absorbance data. Absorbance data at the 5-minute time point were normalized to the total protein content of the homogenate, as determined by comparison with a bovine serum albumin standard curve. Acid phosphatase enzyme activity was reported as moles/minute per milligram protein, and values for each organ were compared with a fixed fraction for kidney (Sewell et al., 1986; Kawashima et al., 1998).

\section{PBPK Model Development}

Base Model Development. The PBPK model for HCQ is represented by eight distinct, flow-limited tissue groupings that could describe HCQ PK based on physiologically-derived metabolism, renal elimination, absorption, macromolecule binding, and lysosomal sequestration. Key features that the model aimed to capture were melanin binding to investigate cases of retinal toxicity, and lysosomal uptake kinetics to model intracellular PK at the active site. Figure 2 depicts a schematic describing the system of these key tissues involved in HCQ PK.

Typically administered orally, HCQ absorption occurs rapidly in the gut lumen, followed by transport to the liver, where it undergoes firstpass metabolism. From there it is distributed to the rest of the body. Key tissues include the kidney, the site of renal excretion, as well as eyes and skin, major sites of melanin binding, and the heart, due to observed instances of cardiomyopathy. The rest of the body is lumped into the slowly perfused compartment, consisting of bone, fat, and muscle, as well as the rapidly perfused compartment, which is composed of the remaining viscera. Additionally, a tumor compartment can be incorporated depending on the location of the primary tumor. Each compartment of the model is further described by a lysosomal subcompartment discussed in the next subsection.

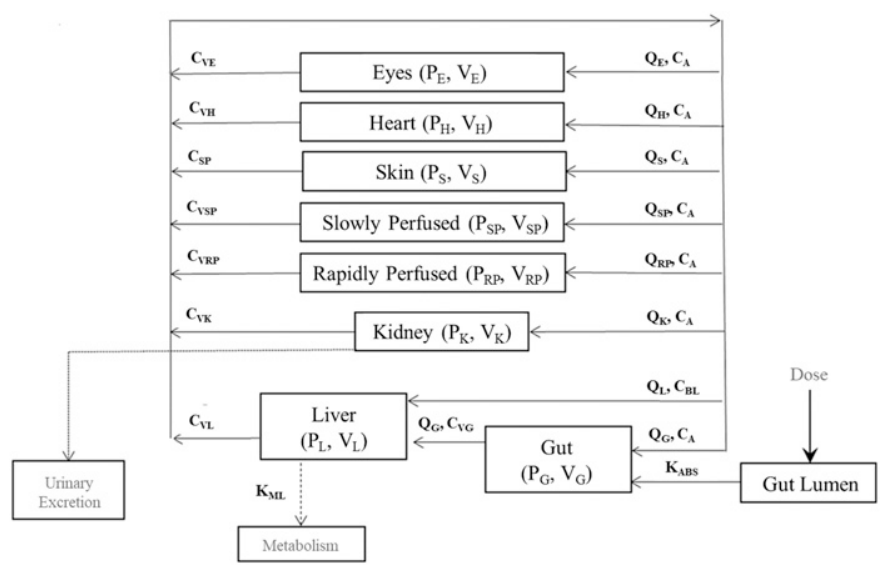

Fig. 2. Schematic of model describing key organs involved in HCQ ADME after oral dosing. Absorption occurs in the gut, metabolism in the liver, and excretion in the kidneys. Skin and eyes exhibit unusual PK properties due to extensive binding to melanin. Heart is included due to cardiomyopathy as an observed side effect in some cases. The rest of the organs are split into slowly perfused (muscle, fat, bone) and rapidly perfused (internal viscera).
Mass balance of a typical tissue observed in the bulk portion of the model is described by eq. 1

$$
\frac{d m_{t}}{d t}=Q_{t} \cdot\left(C_{a}-\frac{C_{t}}{P_{t}}\right)+A_{t} \cdot \Delta J_{l y s}
$$

where $m_{t}$ is the amount of HCQ within the tissue, $Q_{t}$ is the blood flow rate to that tissue, $C_{a}$ is the unbound arterial plasma concentration carried to the tissue, $C_{t}$ is the free concentration within the compartment, $P_{t}$ is the partition coefficient of that tissue, $A_{t}$ is the lysosomal surface area, and $\Delta J_{l y s}$ is the net flux between the cytosol and lysosome. The only tissue with an exception to eq. 1 is the liver, wherein arterial concentration is set to include free drug as well as bound drug due to dissociation of HCQ and protein occurring in the hepatic space (Meijer and van der Sluijs, 1989).

For tissues involved in clearance of $\mathrm{HCQ}$, an additional term is added to eq. 1. For kidney, a renal clearance term is added and is represented by eq. 2 . In the case of liver, a metabolism term is added and is represented by eq. 3 for mouse and eq. 4 for human.

$$
\begin{aligned}
\frac{d m_{\text {renal }}}{d t} & =G F R \cdot Q_{K} \cdot C_{A}+V_{K} \cdot \frac{V_{\text {max }_{\mathrm{sec}}} \cdot C_{A}}{K_{m_{\mathrm{sec}}}+C_{A}} \\
\frac{d m_{m e t}}{d t} & =V_{L} \cdot\left(\frac{C_{L} \cdot V_{\text {max }_{L}}}{K_{m_{L}}+C_{L}}\right) \\
\frac{d m_{m e t}}{d t} & =V_{L} \cdot \mathrm{Met} \cdot C_{L}
\end{aligned}
$$

The first term of eq. 2 accounts for renal filtration in which GFR represents glomerular filtration rate, $Q_{K}$ represents blood flow to the kidney, and $C_{A}$ represents arterial blood concentration. The second term represents active secretion in which $V_{K}$ represents kidney volume, and $V_{\max }$ and $K_{m}$ represent Michaelis-Menten constants for secretion. Equation 3 describes the amount of HCQ metabolized in mouse and is represented by $V_{L}$ and $C_{L}$, the volume and concentration of liver, respectively. It is also represented by $V_{\text {max }}$ and $K_{m}$, Michaelis-Menten rate constants for metabolism. Equation 4 describes the amount of HCQ metabolized in human and is represented by the linear rate constant Met. Melanin binding is the other driving factor of distribution in the model, and so the amount of free HCQ unbound to melanin, applying to skin and eyes, is represented by eq. 5 .

$$
m_{\text {free }}=\frac{m_{c y t}}{\frac{T_{m e l}}{K_{m e l}+C_{t}}}
$$

where $m_{\text {free }}$ is the amount of unbound drug in the cytosol; $m_{\text {cyt }}$ is the total amount in the cytoplasm; $T_{m e l}$, a function of melanin/HCQbinding ratio $\left(\mathrm{Mel}_{\mathrm{BR}}\right)$ and melanin concentration in the tissue $\left(\mathrm{Ct}_{\mathrm{mel}}\right)$, is the binding capacity of melanin for $\mathrm{HCQ} ; K_{m e l}$ is the binding affinity of HCQ to melanin; and $C_{t}$ is the free concentration in the cytosol. Values for $T_{m e l}$ and $K_{m e l}$ were estimated from a previous study on HCQ binding (Schroeder and Gerber, 2014), and melanin concentrations for skin and eye have been reported (Durairaj et al., 2012; Browning, 2014). The parameters for the PBPK model can be found in Table 1 along with the source of each variable.

ADME Parameters. Tissue volumes and blood flows were standard, fixed values, as previously described (Brown et al., 1997). The only exception was eye, which came from multiple sources (Choi et al., 2012; Zhi et al., 2012).

Absorption parameters were obtained from a prior study (Tett et al., 1989). Specifically, the absorption rate constant was modeled as linear uptake that achieved near-full absorption within an average of 3 hours. Fraction absorbed was set to an average of $0.75 \pm 0.13$ of the dose, as described by human urine and blood data. First-pass hepatic effect was deemed insignificant in this study as well, and was calculated at only $6 \%$ of the total dose. Biliary secretion was initially considered, as fecal excretion of HCQ in rat was cited as $25 \%$ of total 
TABLE 1

PBPK model variables

\begin{tabular}{|c|c|c|c|c|}
\hline Tissue Volume & Symbol & Mouse & Human & Reference \\
\hline Kidney & of Podv woinht & 1.7 & 0.4 & Brown et al. (1997) \\
\hline Heart & & 0.5 & 0.5 & Brown et al. (1997) \\
\hline Eye & & $0.034(\mathrm{~g})$ & $15(\mathrm{~g})$ & $\begin{array}{l}\text { Mou-Experimental; } \\
\text { Hum-Brittanica }\end{array}$ \\
\hline Skin & & 16.5 & 3.7 & Brown et al. (1997) \\
\hline Gut & & 4.2 & 1.4 & Brown et al. (1997) \\
\hline Liver & & 5.5 & 2.57 & Brown et al. (1997) \\
\hline Blood & & 4.9 & 7.9 & Brown et al. (1997) \\
\hline Slowly perfused & & 56.1 & 75.7 & Brown et al. (1997) \\
\hline Rapidly perfused & & 10.4 & 7.5 & Brown et al. (1997) \\
\hline \multicolumn{5}{|l|}{ Tissue blood flow } \\
\hline Kidney & o Cardiac outnut & 9.1 & 17.5 & Brown et al. (1997) \\
\hline Heart & 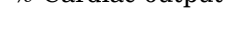 & 6.6 & 4.0 & Brown et al. (1997) \\
\hline Eye & & 0.0566 & 0.00164 & $\begin{array}{l}\text { Mou-Zhi et al. (2012); } \\
\text { Hum-Choi et al. (2012) }\end{array}$ \\
\hline Skin & & 5.8 & 5.8 & Brown et al. (1997) \\
\hline Gut & & 14.1 & 18.1 & Brown et al. (1997) \\
\hline Liver & & 2.0 & 4.6 & Brown et al. (1997) \\
\hline Slowly perfused & & 34.2 & 28.5 & Brown et al. (1997) \\
\hline Rapidly perfused & & 28.1 & 21.5 & Brown et al. (1997) \\
\hline \multicolumn{5}{|l|}{ Tissue partioning $^{a}$} \\
\hline Kidney & PK & 50 & 50 & Wei et al. (1995) \\
\hline Heart & $\mathrm{PH}$ & 44 & 44 & Wei et al. (1995) \\
\hline Eye & $\mathrm{PE}$ & 33 & 33 & Wei et al. (1995) \\
\hline Skin & PS & 26 & 26 & Wei et al. (1995) \\
\hline Gut & PG & 35 & 35 & McChesney et al. (1967) \\
\hline Liver & PL & 193 & 193 & Wei et al. (1995) \\
\hline Blood & $\mathrm{PB}$ & 7.2 & 7.2 & Tett et al. (1988) \\
\hline Slowly perfused & PSP & 10 & 10 & $\begin{array}{l}\text { McChesney et al. (1967); } \\
\text { Wei et al. (1995) }\end{array}$ \\
\hline $\begin{array}{l}\text { Rapidly perfused } \\
\text { Metabolism }^{b}\end{array}$ & PRP & 150 & 150 & Wei et al. (1995) \\
\hline Metabolism affinity & $\mathrm{Km}_{\mathrm{L}}(\mu \mathrm{M})$ & 357 & & Optimized from mouse PK \\
\hline Metabolism max rate & $\operatorname{Vmax}_{\mathrm{L}}(\mu \mathrm{M} / \mathrm{h})$ & 1171 & & Optimized from mouse PK \\
\hline Metabolism rate constant & Met $\left(h^{-1}\right)$ & & 0.154 & $\begin{array}{l}\text { Optimized from human } \\
\text { liver microsomes }\end{array}$ \\
\hline \multicolumn{5}{|l|}{ Clearance $^{c}$} \\
\hline Plasma protein binding & $\%$ bound & 0.45 & 0.45 & Browning (2014) \\
\hline Glomerular filtration rate & GFR & 0.125 & 0.11 & Mou—Qi and Breyer (2009) \\
\hline Secretion affinity & $\mathrm{Km}_{\mathrm{sec}}(\mu \mathrm{M})$ & 1000 & 1000 & Optimization \\
\hline Secretion max rate & $\operatorname{Vmax}_{\sec }(\mu \mathrm{M} / \mathrm{h})$ & 32,500 & 32,500 & Optimization \\
\hline $\begin{array}{l}\text { Intestinal absorption } \\
\text { Absorntion rate }\end{array}$ & & & & Tett et al. (1989) \\
\hline $\begin{array}{l}\text { Absorption rate } \\
\text { Absorption fraction }\end{array}$ & $\begin{array}{c}\mathrm{KA}(\mathrm{h}) \\
\mathrm{FA}\end{array}$ & & $\begin{array}{l}0.5 \\
0.75\end{array}$ & $\begin{array}{l}\text { Tett et al. (1989) } \\
\text { Tett et al. (1989) }\end{array}$ \\
\hline \multicolumn{5}{|l|}{ Melanin binding ${ }^{d}$} \\
\hline Melanin affinity & $\mathrm{Km}_{\text {mel }}(\mu \mathrm{M})$ & & 217 & Schroeder and Gerber (2014) \\
\hline Binding ratio & $\mathrm{HCQ}_{\mathrm{mel}}$ & & 0.178 & Schroeder and Gerber (2014) \\
\hline Eye melanin concentration & $\mathrm{CE}_{\mathrm{ME}}(\mu \mathrm{M})$ & & $2.4 \mathrm{E} 04$ & Durairaj et al. (2012) \\
\hline Skin melanin concentration & $\mathrm{CS}_{\mathrm{ME}}(\mu \mathrm{M})$ & & 300 & Browning (2014) \\
\hline
\end{tabular}

${ }^{a}$ Most partition coefficients were optimized from McChesney et al. (1967), Wei et al. (1995), and Tett et al. (1998). Slowly perfused was an average value of adipose from McChesney et al. (1967) and Wei et al. (1995).

${ }^{b}$ Values for mouse were calculated from liver PK data; human rate constant was calculated from human liver microsomes and optimized to meet the ratio of metabolism vs. clearance reported by Tett et al. (1988, 1989).

${ }^{c}$ Total renal clearance was a function of plasma protein binding and GFR, with secretion coefficients optimized to meet total renal clearance values in tandem with metabolism reported by Tett et al. $(1988,1989)$.

${ }^{d}$ Melanin binding parameters were taken from a bunch of sources and optimized for human. Skin melanin is for an average person of light colored skin. The value increases up to 4 times based on skin color.

dose (McChesney, 1983); however, ratio of metabolite versus parent was not observed. Biliary secretion was tested in the model, assuming complete absorption, and was representative of a model lacking biliary clearance with $0.85-0.9$ fraction absorbed. As this fell within the range of absorption fraction observed in humans, biliary secretion was not considered a major driving factor of HCQ PK and was omitted from the model.

Distribution of the bulk model was primarily described by partition coefficients, the concentration ratio between plasma and tissue at steady state. The partition coefficient values were derived and optimized using previously published data (McChesney et al., 1967; Tett et al., 1989; Wei et al., 1995).
Metabolism values for mouse were obtained and optimized from liver PK data by determining the Michaelis-Menten relationship that represented the compartmental clearance of this region. The human metabolism rate constant was obtained by incubating HCQ with activated human liver microsomes, as described in the microsome section of Materials and Methods, and optimized to best fit human PK data. Intrinsic scaling of in vitro to in vivo metabolism for CYP450 enzymes, as previously described (Chiba et al., 2009), was not considered because moderate optimization of the microsome-derived metabolism rate yielded clearance that fit the clinical data well, and satisfied the hepatic clearance portion observed in human patients (Tett et al., 1988). Intestinal metabolism was considered negligible 
due to the significantly lower CYP3A and 2C levels observed in intestine compared with liver as well as low first-pass metabolism (Thelen and Dressman, 2009).

Excretion was modeled as filtration and secretion because mean renal clearance was found to be 3 to 4 times greater than GFR (Tett et al., 1988, 1989, 1990). GFR was set to 0.125 for mouse (Qi and Breyer, 2009) and 0.11 for human of the unbound plasma flow to the renal tubules. The $\mathrm{Km}$ and Vmax for renal secretion were optimized using the Nelder-Mead method to best fit the data, accounting for 3 to 4 times GFR as secretion as well as the $\sim 3: 1$ ratio of nonrenal clearance (assumed to be liver clearance) to total renal clearance upon scaling from mouse to human (Tett et al., 1990; Furst, 1996).

Lysosomal Compartment Development. Within each tissue compartment was a lysosomal subcompartment that was mathematically described as separate from its parent compartment. The subcompartment was modeled to represent the ion trap effect that causes HCQ accumulation to millimolar concentrations in acidic regions, primarily the lysosome. A schematic of lysosomal sequestration is represented in Fig. 3, which depicts $\mathrm{HCQ}$ and $\mathrm{HCQ}^{+}$moving freely across membranes at physiologic $\mathrm{pH}$, but, upon entering the acidic lysosome, a majority of $\mathrm{HCQ}$ is in the $2^{+}$state, where it can no longer permeate the membrane and becomes trapped.

The mass balance of the lysosomal subcompartment for each tissue is represented by the second term in eq. 1 and is described by eq. 6 :

$$
\frac{d m_{l y s}}{d t}=A_{t} \cdot \Delta J_{l y s}
$$

where $A_{t}$ represents the lysosomal surface area and $\Delta J_{l y s}$ represents the net flux between the cytosol and lysosome compartments. The flux portion was adapted from the cell model proposed by Trapp et al. (2008) that describes lysosomal drug uptake on a cellular pharmacokinetic level. It was validated using a select handful of drugs with a variety of $\mathrm{pKa}$ and lipophilicity values, one of which was chloroquine (Trapp and Horobin, 2005; Trapp et al., 2008). The overarching principle in their cell model was application of Fick's first law of diffusion with the Nernst-Planck equation, which incorporates electric charge into the movement of molecules through a biologic environment. Fick's first Law of Diffusion, which only applies to the neutral form of HCQ $\left(J_{n}\right)$, is depicted by eq. 7 , and the combined Fick's-Nernst-Planck version of diffusion $\left(J_{d}\right)$ is eq. 8 . These equations are combined to yield eq. 9:

$$
\begin{aligned}
J_{n} & =f_{n} P_{n} C \\
J_{d} & =f_{d} D_{z} P_{d} C \frac{N}{e^{N}-1} \\
\Delta J_{l y s} & =\left(J_{n}+J_{d}\right)_{l y s}-\left(J_{n}+J_{d}\right)_{c y t}
\end{aligned}
$$

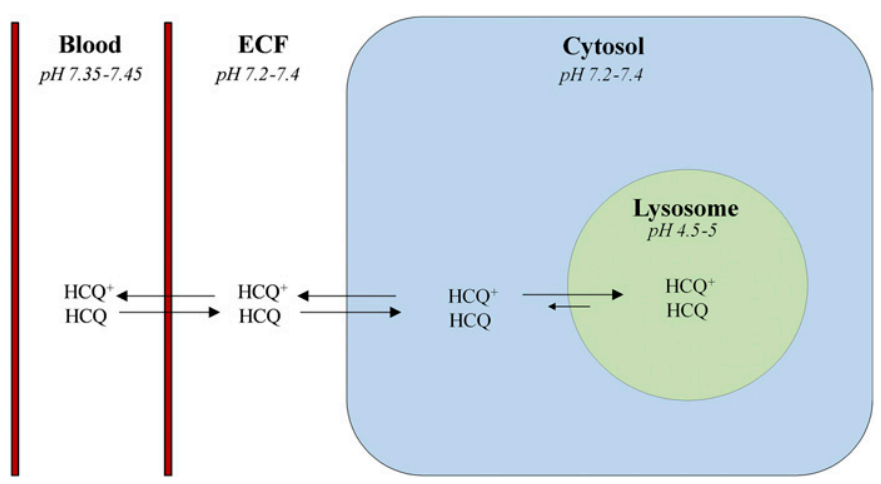

Fig. 3. Intracellular mechanism of $\mathrm{HCQ} P K$ with $\mathrm{pH}$ dependence. HCQ crosses membranes readily, but accumulates in acidic compartments due to being nonpermeable in the +2 state. where $f_{n}$ represents the fraction of freely dissolved neutral HCQ, described by eq. 10 [or reference eq. 6 from Trapp et al. (2008) for a more derived description]. $P_{n}$ and $P_{d}$ represent the permeabilities of neutral and ionic HCQ states, $D_{z}$ is the Henderson-Hasselbach activity ratio, $C$ is the total $\mathrm{HCQ}$ concentration in the compartment (applying to either cytosol or lysosome), and $N$ is the Nernst equation. Equations 7 and 8 represent HCQ flux in the neutral and ionic states and are combined to give the net flux between both compartments in eq. 9. The fraction of freely dissolved HCQ in this equation is represented by $f_{n}$ and is described by eq. 10 :

$$
f_{n}=\left(\frac{W+K_{n}}{\gamma_{n}}+\frac{D_{1} W+D_{1} K_{1}}{\gamma_{1}}+\frac{D_{2} W+D_{2} K_{2}}{\gamma_{2}}\right)^{-1}
$$

which represents the fraction of HCQ in the system that is available to move. This description has been well described previously (Trapp et al., 2008), but briefly it represents the fraction available to move by taking into account lipid binding, sorption, and ionic activity. $W$ represents water fraction in the compartment, L represents lipid fraction in the compartment, $K_{n}$ and $K_{z}$ are sorption coefficients of neutral and ionic HCQ, and $\gamma$ represent the ionic activity coefficients for the compartment.

The effect of charge on lipophilicity of a molecule, which sets the framework for the ionic sorption coefficents $\left(K_{z}\right)$ and ionic permeability, has been previously described (Trapp et al., 2008). The equation for charged lipophilicity is shown in eq. 11:

$$
\text { Kow }_{z}=10^{\log _{10}(\text { Kow })-3.5 z}
$$

where $z$ is the charge HCQ. Equation 11 is applied to the permeability (eq. 12) and sorption (eq. 13) to represent these properties of charged HCQ:

$$
\begin{aligned}
& P_{z}=10^{\log _{10}\left(\mathrm{Kow}_{z}\right)-1.1427} \\
& K_{z}=1.22 \cdot \mathrm{L} \cdot \mathrm{Kow}_{z}
\end{aligned}
$$

Additionally, eq. 8 incorporates the Henderson-Hasselbach activity ratio, $D_{z}$, which represents the ratio between neutral and ionic fractions of the molecule. $D_{z}$ is represented by eq. 14 for the $1^{+}$state and eq. 15 for the $2^{+}$state.

$$
\begin{aligned}
& D_{1}=10^{\left(p K a_{1}-p H\right)} \\
& D_{2}=10^{\left(p K a_{1}+p K a_{2}-2 p H\right)}
\end{aligned}
$$

All values of physicochemical properties of HCQ and lysosomal properties used in equations related to this section of the model can be found in Table 2 along with the source of these values (Kawashima et al., 1998; Ishizaki et al., 2000; Warhurst et al., 2003; Trapp et al., 2008).

An additional component to consider at the cellular scale is the effect of lysosomal HCQ accumulation on $\mathrm{pH}$. Previous studies have demonstrated the $\mathrm{pH}$ neutralization effect of weak base accumulation in lysosomes (Ohkuma and Poole, 1978), and this has been taken into account in more recently developed cellular models (Ishizaki et al., 2000; Kornhuber et al., 2010). Equation 16 was used to describe the dynamic $\mathrm{pH}$ of the lysosome compartment:

$$
\Delta p H=\frac{C_{l y s}}{\beta}
$$

where $C_{l y s}$ is the free lysosomal concentration and $\beta$ is the buffering capacity, as previously described (Ishizaki et al., 2000). Dynamic $\mathrm{pH}$ affects the free fraction of HCQ in each ionic state, which causes net flux to approach an equilibrium as lysosome $\mathrm{pH}$ becomes more neutral. Dynamic $\mathrm{pH}$ based on buffering capacity was not considered for the cytosolic compartment. Initial $\mathrm{pH}$ values for lysosome and cytosol compartments were the same for all tissues and were set to 5.0 and 7.2 , respectively. 
TABLE 2

Physicochemical properties of HCQ and lysosomal properties

\begin{tabular}{lccl}
\hline \multicolumn{1}{c}{ Drug Constants } & Symbol & Value & \multicolumn{1}{c}{ Reference } \\
\hline Molecular weight & $\mathrm{Mol}_{\text {. wt. }}$ & 335.872 & \\
Lipophilicity & $\mathrm{Log}_{10}(\mathrm{Kow})$ & 3.84 & Warhurst et al. (2003) \\
First dissociation constant & $\mathrm{pKa}_{1}$ & 9.67 & \\
Second dissociation constant & $\mathrm{pKa}_{2}$ & 8.27 & \\
Lysosomal parameters & & & \\
Lysosomal lipid fraction & $\mathrm{L}$ & 0.05 & Trapp et al. (2008) \\
Lysosomal water fraction & $\mathrm{W}$ & 0.95 & Trapp et al. (2008) \\
Neutral activity coefficient & $\gamma_{\mathrm{N}}$ & 1.23 & Trapp et al. (2008) \\
First activity coefficient & $\gamma_{1}$ & 0.74 & Trapp et al. (2008) \\
Second activity coefficient & $\gamma_{2}$ & 0.3 & Trapp et al. (2008) \\
Lysosomal radius & $\mathrm{r}_{\text {lys }}(\mu \mathrm{m})$ & 0.275 & Kawashima et al. (1998) \\
Lysosomal buffering capacity & $\beta(\mathrm{mM})$ & 46 & Ishizaki et al. (2000) \\
Lysosomal pH & $\mathrm{pH}_{\mathrm{lys}}$ & 5.0 & Trapp et al. (2008) \\
Cytosolic pH & $\mathrm{pH}_{\text {cyt }}$ & 7.2 & Trapp et al. (2008) \\
Lysosome content & & & \\
Kidney & & 0.05 & \\
Heart & Tissue volume & 0.1 & \\
Eye & & 0.015 & \\
Skin & & 0.1 & \\
Gut & & 0.1 & \\
Liver & & 0.05 & \\
Slowly perfused & & 0.1 & \\
Rapidly perfused & & 0.2 & \\
\hline
\end{tabular}

${ }^{a}$ Starting values from Sewell et al. (1986) and Kawashima et al. (1998). Final values determined from acid phosphatase and optimization.

Volume of the lysosome compartment for each tissue was determined by total acid phosphatase activity in the tissue. Acid phosphatase activity was assumed to correlate directly with total lysosomal volume fraction of the tissue. Acid phosphatase activity/lysosome volume fraction was compared between tissues on a ratio basis using a set value for kidney lysosome volume fraction, and optimized to fit the mouse model (Sewell et al., 1986; Kawashima et al., 1998). Lysosome size was set to a constant spherical volume using a radius of $275 \mathrm{~nm}$.

\section{Data Analysis}

The ability of the model to accurately predict concentration-time profiles was analyzed by comparing PBPK simulation pharmacokinetic variables with those of actual data, as well as through calculation of the median absolute performance error (MAPE\%) and the median performance error (MPE\%). The performance error (PE) of the model was calculated as the difference between the measured and simulated concentrations normalized to the simulated concentration, as shown in eq. 17:

$$
P E=\frac{C_{\text {measured }}-C_{\text {simulated }}}{C_{\text {simulated }}} \cdot 100
$$

The MAPE\%, which measures prediction accuracy, was calculated by eq. 18:

$$
M A P E \%=\left(\left|P E_{1}\right|,\left|P E_{2}\right|, \ldots\left|P E_{N}\right|\right)
$$

where $N$ represents the total number of samples for the given tissue. The MPE\%, which is a measure of positive or negative prediction bias, was calculated by eq. 19 :

$$
M P E \%=\operatorname{median}\left(P E_{1}, P E_{2}, \ldots P E_{N}\right)
$$

\section{Computer Simulation and Software}

PBPK model development and simulation were done in Advanced Continuous Simulation Language Xtreme (acslX), version 3.1.4.2, from Aegis Technologies Group (Huntsville, AL). Pharmacokinetic evaluation of simulated and clinical data was done on Phoenix 64 build 7.0.0.2535.

\section{Results}

HCQ Model Simulations in Mice. PK data from mice were generated following a single i.p. dose of 20,40, or $80 \mathrm{mg} / \mathrm{kg}$ HCQ. Tissues and whole blood were collected from mice at $3,6,12,24,48$, and 72 hours after dosing. The PBPK model was developed from the following tissues in this study: whole blood, liver, kidney, and gut. Figure 4 shows the HCQ PK profile from these mice compared with PBPK-generated simulation data. In addition to whole-tissue PK, the contributions of lysosomal subcomponents were examined and are found in Supplemental Fig. 1. Lysosomal HCQ PK profiles were similar between tissues, and simulated concentrations peaked between 20 and $40 \mathrm{mM}$, which are consistent with lysosomal concentrations of lysosomotropic agents reported in previous studies (Browning, 2014).

The ability of the model to accurately predict the concentration-time profile of HCQ was determined through calculation of MAPE\% and MPE\% presented as a percentage for tissues and whole blood, shown in Table 3. MAPE\% is a method of determining model accuracy, whereas MPE\% indicates under- or overprediction bias (Sheiner and Beal, 1981). Overall, MAPE\% for each dosing cohort were within similar ranges. The ranges were $27 \%-73 \%, 19 \%-71 \%$, and $24 \%-44 \%$ for 20,40 , and $80 \mathrm{mg} / \mathrm{kg}$, respectively. Upper bounds of this range were skewed by the deviation of model simulation from actual PK data for liver after 24 hours due to the concentration-time profile for HCQ PK dropping to zero after 24 hours. The model prediction follows the actual data well for the first 24 hours, after which it predicts a slower decline at these later time points. Removing the liver MAPE\% drops the ranges to $27 \%-39 \%, 19 \%-27 \%$, and $24 \%-37 \%$. Comparing this range of $\mathrm{MAPE} \%$ with the variation in actual $\mathrm{PK}$ data, 
A
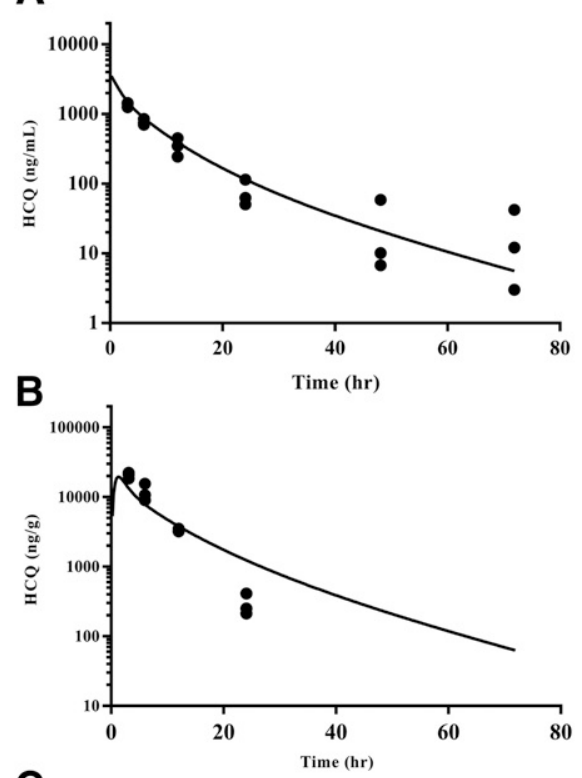

C
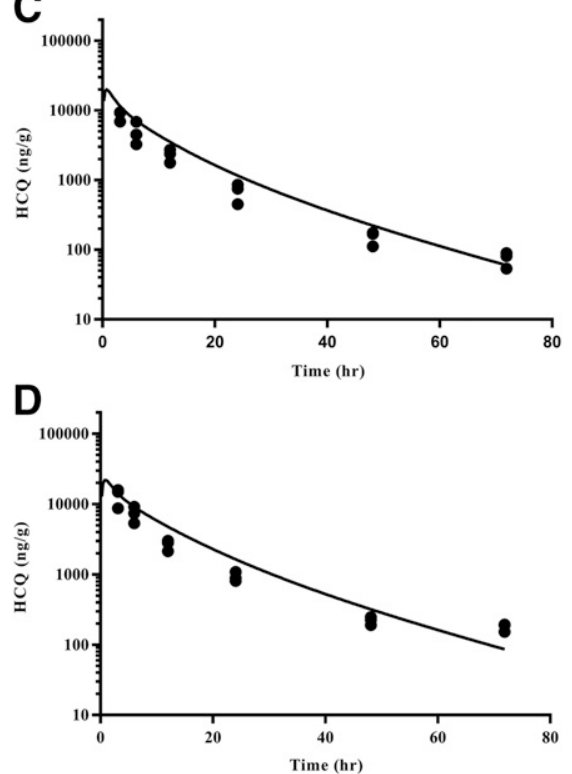
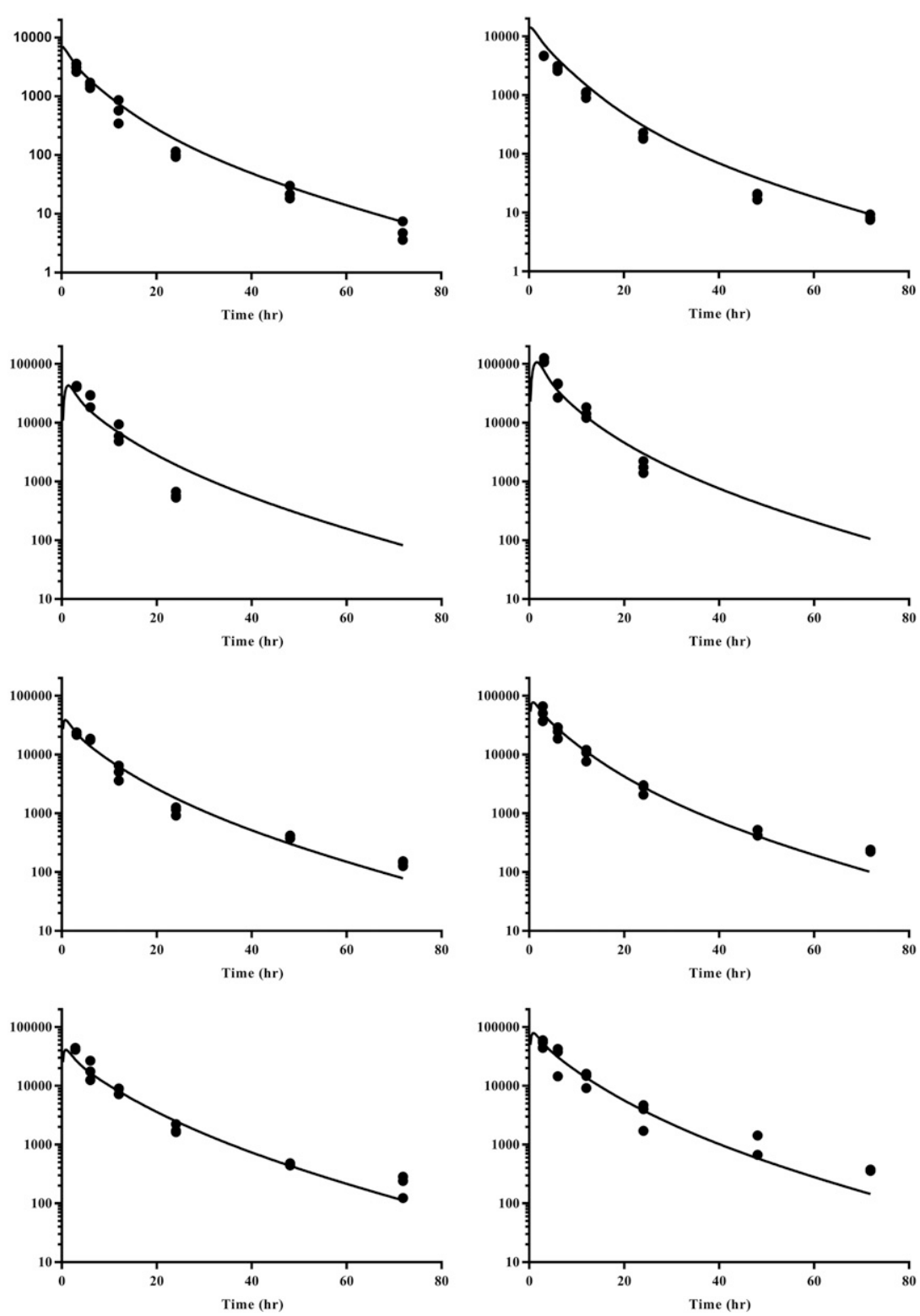

Fig. 4. Mouse PK data compared with PBPK simulation. Mice were treated with a single i.p. dose of HCQ at 20, 40, and $80 \mathrm{mg} / \mathrm{kg}$ (left, middle, and right columns), and data were collected at $3,6,12,24,48$, and 72 hours from whole blood (A), liver (B), kidney (C), and gut (D). Circles represent tissues from treated mice (three replicates per time point, $n=54$ ), and lines represent simulation output.

determined by the range of average coefficient of variation for each dosing cohort, is a strong indicator of whether model prediction is within the dispersion of the actual data. Coefficient of variation values for the PK cohorts are $16 \%-43 \%$, $9 \%-20 \%$, and $8 \%-28 \%$ for 20,40 , and $80 \mathrm{mg} / \mathrm{kg}$, respectively, which are quite similar to the MAPE\% for the respective cohorts. This suggests that the model accounts for a majority of natural variation within the clinical data. Taking into account MPE\%, the model tends to slightly overpredict blood and liver concentrations in each dose cohort. Kidney and gut are overpredicted in the $20 \mathrm{mg} / \mathrm{kg}$ cohort, but slightly underpredicted in the 40 and $80 \mathrm{mg} / \mathrm{kg}$ mice, indicating no significant bias in over- or underprediction of the model. An additional method of determining the model's predictive capability was through comparison of simulation versus actual pharmacokinetic variables generated through NCA, which are presented in Table 4.

The NCA variables compared for blood and each tissue were terminal $t_{1 / 2}$ and area under the curve (AUC). Values of each were determined over the 72-hour interval and compared ratiometrically (actual/simulated). Overall, the AUC ratios were very close to one, indicating a high degree of accuracy within the model. The $t_{1 / 2}$ were also relatively close, except for liver 20 and $40 \mathrm{mg} / \mathrm{kg}$ cohorts, which, as noted with MAPE\%, are due to the lack of a terminal phase in the actual liver data. Although $t_{1 / 2}$ ratios were low for each dosing cohort, the ratios near one for AUC indicate that the model predicts overall liver exposure with a high degree of accuracy.

HCQ Model Simulations in Humans. After validating the simulation in mice, the model was scaled to human 
TABLE 3

Measure of predictive performance of the PBPK model for mouse (tissues) and human (blood and urine) data

\begin{tabular}{cccr}
\hline Dose & Tissue/Patient & MAPE\% & MPE\% \\
\hline $20 \mathrm{mg} / \mathrm{kg}$ & Blood & 27.25 & -11.06 \\
& Liver & 73.25 & -41.16 \\
& Kidney & 33.89 & -25.28 \\
& Gut & 39.35 & -31.87 \\
$40 \mathrm{mg} / \mathrm{kg}$ & Blood & 23.93 & -23.93 \\
& Liver & 71.31 & -46.90 \\
& Kidney & 27.48 & 8.17 \\
& Gut & 18.52 & 8.08 \\
$80 \mathrm{mg} / \mathrm{kg}$ & Blood & 37.01 & -37.01 \\
& Liver & 43.80 & -24.80 \\
& Kidney & 24.19 & 5.90 \\
& Gut & 23.52 & 9.90 \\
$200 \mathrm{mg}$ (oral) & 4 (blood) & 18.64 & 14.79 \\
& 5 (urine) & 15.53 & -3.34 \\
$200 \mathrm{mg}$ (i.v.) & 4 (blood) & 33.51 & -11.58 \\
& 5 (urine) & 20.99 & 9.55 \\
& 1 (blood) & 42.13 & 17.36 \\
$400 \mathrm{mg}$ (i.v.) & 1 (blood) & 39.32 & 20.82 \\
\hline
\end{tabular}

patients by adjusting appropriate physiologic parameters, which are compared in Table 1. Concentration-time data for individual humans were used (Tett et al., 1988, 1989) and included both oral and i.v. infusion doses of 200 and $400 \mathrm{mg}$ HCQ sulfate. Whole-blood data were available for two patients (patients 1 and 4) from this study, and cumulative urinary excretion of HCQ was available for another (patient 5). The concentration-time profile between simulation and actual data was compared over a 72-hour time period and is presented in Fig. 5. In addition to whole-blood PK, tissue concentrations were simulated following these dosing schemes as well and can be found in Supplemental Fig. 2. Simulated PK profiles for each of the dosing routes were notably different from each other, specifically in that liver and gut peak concentrations were approximately 2 to 3 times higher, and kidney much lower, in patients receiving oral versus i.v. infusion dosing due to the absorption phase. Lysosomal PK for these human tissues was also simulated following these dosing schemes and can be found in Supplemental Fig. 3. Peak concentrations are similar to those in mice, at $20-30 \mathrm{mM}$ in liver and gut, and as low as $6 \mathrm{mM}$ in kidney following $200 \mathrm{mg}$ oral dosing.

As individual physiologic data were not available for the human patients, generic human physiologic parameters were assumed (see Table 1) for patients 4 and 5 (Brown et al., 1997). After fitting the model to these patients through optimization of absorption, metabolism, and renal clearance parameters, the model was fit to patient 1 by simply increasing body weight from 70 to $85 \mathrm{~kg}$. For the human model, the MAPE\% range, presented in Table 3, for whole blood was between 19\% and $42 \%$, and for urine was between $16 \%$ and $21 \%$, indicating strong predictive power of the model. As this was individual patient data, the coefficient of variation was not reported for comparison with these patients. MPE\% indicated a slight underprediction of the actual PK profile for all of those compared except patient 4 i.v. infusion, which was a slight overprediction.

NCA parameters were also compared for human wholeblood data and can be found in Table 4. Overall, the actual/simulation ratios of $t_{1 / 2}$ and AUC indicated strong predictive power of the model.

TABLE 4

NCA parameter comparison between actual PK- and PBPK-simulated data

\begin{tabular}{|c|c|c|c|c|c|c|}
\hline Mouse & Tissue & & $\mathrm{t}_{1 / 2}(\mathrm{~h})$ & $\mathrm{AUC}(\mathrm{h} \times \mu \mathrm{g} / \mathrm{ml})$ & $\mathrm{t}_{1 / 2}$ (Ratio) & AUC (Ratio) \\
\hline \multirow[t]{4}{*}{$20 \mathrm{mg} / \mathrm{kg}$} & Blood & $\begin{array}{c}\text { Actual } \\
\text { Simulated }\end{array}$ & $\begin{array}{c}24.09 \pm 8.84 \\
12.91\end{array}$ & $\begin{array}{c}10.84 \pm 0.63 \\
11.22\end{array}$ & 1.87 & 0.97 \\
\hline & Liver & Actual & $3.38 \pm 0.37$ & $116.93 \pm 11.16$ & 0.49 & 1.08 \\
\hline & Kidney & Actual & $15.12 \pm 0.72$ & $72.25 \pm 2.69$ & 1.17 & 0.73 \\
\hline & Gut & $\begin{array}{l}\text { Simulated } \\
\text { Actual } \\
\text { Simulated }\end{array}$ & $\begin{array}{c}12.96 \\
20.45 \pm 2.00 \\
12.97\end{array}$ & $\begin{array}{c}99.01 \\
100.55 \pm 15.03 \\
131.80\end{array}$ & 1.58 & 0.76 \\
\hline \multirow[t]{4}{*}{$40 \mathrm{mg} / \mathrm{kg}$} & Blood & $\begin{array}{c}\text { Actual } \\
\text { Simulated }\end{array}$ & $\begin{array}{c}11.2 \pm 1.49 \\
12.67\end{array}$ & $\begin{array}{c}19.50 \pm 0.66 \\
21.89\end{array}$ & 0.88 & 0.89 \\
\hline & Liver & $\begin{array}{c}\text { Actual } \\
\text { Simulated }\end{array}$ & $\begin{array}{l}3.31 \pm 0.17 \\
6.00\end{array}$ & $\begin{array}{c}244.87 \pm 33.98 \\
198.19\end{array}$ & 0.55 & 1.24 \\
\hline & Kidney & $\begin{array}{c}\text { Actual } \\
\text { Simulated }\end{array}$ & $\begin{array}{c}16.24 \pm 1.24 \\
12.74\end{array}$ & $\begin{array}{c}191.54 \pm 12.56 \\
175.82\end{array}$ & 1.27 & 1.09 \\
\hline & Gut & $\begin{array}{c}\text { Actual } \\
\text { Simulated }\end{array}$ & $\begin{array}{c}15.82 \pm 3.20 \\
12.76\end{array}$ & $\begin{array}{c}272.23 \pm 18.75 \\
222.82\end{array}$ & 1.24 & 1.22 \\
\hline \multirow[t]{4}{*}{$80 \mathrm{mg} / \mathrm{kg}$} & Blood & $\begin{array}{c}\text { Actual } \\
\text { Simulated }\end{array}$ & $\begin{array}{c}10.51 \pm 0.52 \\
12.45\end{array}$ & $\begin{array}{c}33.27 \pm 2.25 \\
44.17\end{array}$ & 0.84 & 0.75 \\
\hline & Liver & $\begin{array}{c}\text { Actual } \\
\text { Simulated }\end{array}$ & $\begin{array}{c}4.03 \pm 0.88 \\
5.07\end{array}$ & $\begin{array}{c}512.92 \pm 44.22 \\
400.70\end{array}$ & 0.79 & 1.28 \\
\hline & Kidney & $\begin{array}{c}\text { Actual } \\
\text { Simulated }\end{array}$ & $\begin{array}{c}13.77 \pm 0.76 \\
12.53\end{array}$ & $\begin{array}{c}339.17 \pm 4.11 \\
322.20\end{array}$ & 1.10 & 1.05 \\
\hline & Gut & $\begin{array}{c}\text { Actual } \\
\text { Simulated }\end{array}$ & $\begin{array}{c}16.04 \pm 3.65 \\
12.43\end{array}$ & $\begin{array}{c}432.80 \pm 97.44 \\
385.13\end{array}$ & 1.29 & 1.12 \\
\hline \multirow[b]{2}{*}{$200 \mathrm{mg}$-Patient 4 (oral) } & & & & & & \\
\hline & Blood & $\begin{array}{c}\text { Actual } \\
\text { Simulated }\end{array}$ & $\begin{array}{l}77.47 \\
77.24\end{array}$ & $\begin{array}{l}5.57 \\
5.54\end{array}$ & 1.00 & 1.01 \\
\hline $200 \mathrm{mg}$-Patient 4 (i.v.) & Blood & $\begin{array}{c}\text { Actual } \\
\text { Simulated }\end{array}$ & $\begin{array}{l}84.90 \\
73.45\end{array}$ & $\begin{array}{l}5.85 \\
7.51\end{array}$ & 1.16 & 0.78 \\
\hline 200 mg-Patient 1 (i.v.) & Blood & $\begin{array}{c}\text { Actual } \\
\text { Simulated }\end{array}$ & $\begin{array}{l}54.58 \\
77.76\end{array}$ & $\begin{array}{l}5.23 \\
5.86\end{array}$ & 0.70 & 0.89 \\
\hline $400 \mathrm{mg}$-Patient 1 (i.v.) & Blood & $\begin{array}{c}\text { Actual } \\
\text { Simulated }\end{array}$ & $\begin{array}{r}117.50 \\
68.25\end{array}$ & $\begin{array}{l}10.01 \\
12.55\end{array}$ & 1.72 & 0.80 \\
\hline
\end{tabular}



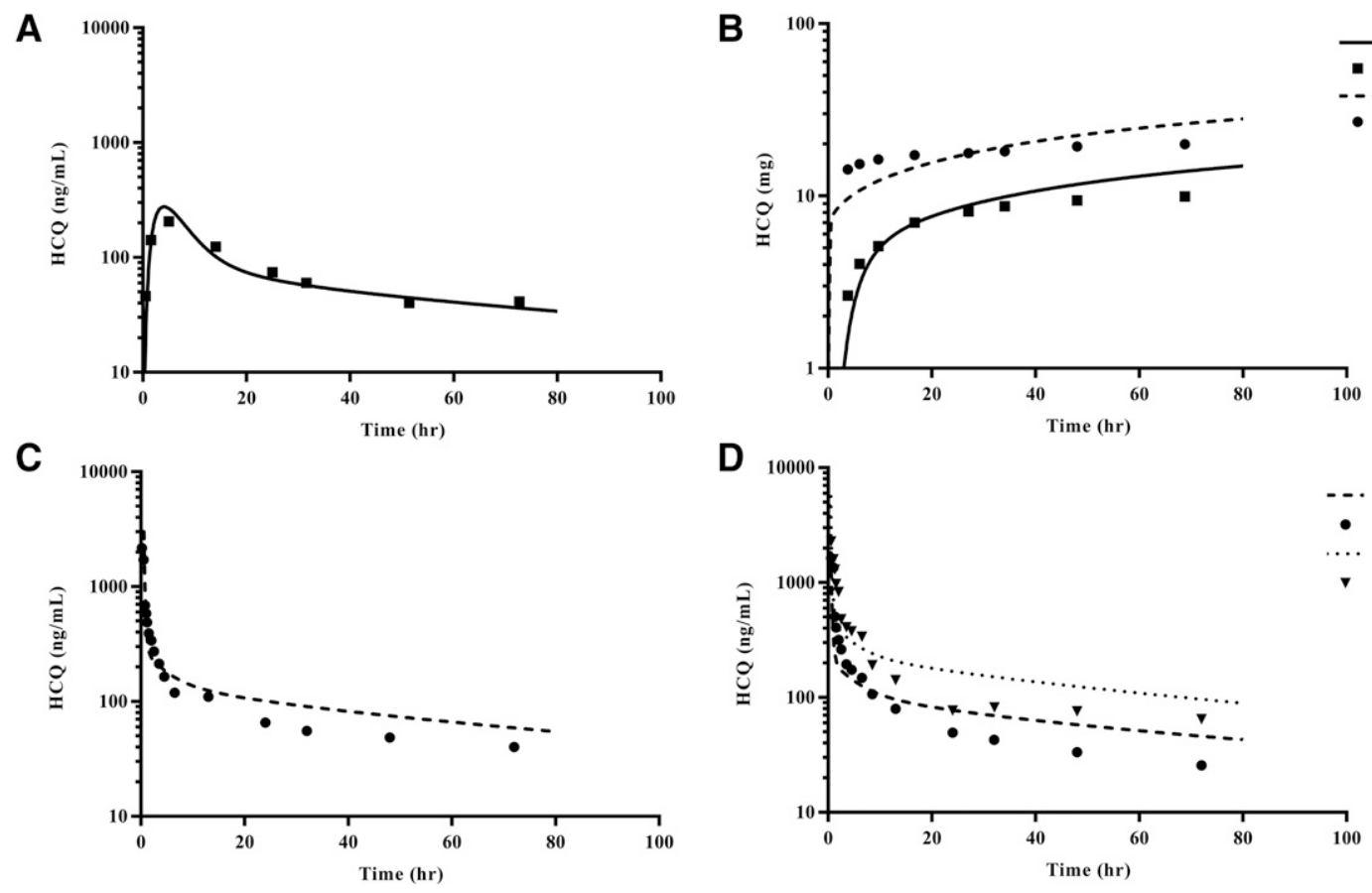

Fig. 5. Human whole-blood and urine concentrations of HCQ (points) were compared with PBPK simulation (lines) (Tett et al., 1988, 1989). Whole-blood concentrations of patient 4 from the studies were simulated after a single $200 \mathrm{mg}$ oral dose (A). Urinary excretion of HCQ was simulated in patient 5 from the studies following $200 \mathrm{mg}$ oral and i.v. doses (B). Whole-blood concentrations of patient 4 from the studies were simulated after a single 200 mg i.v. infusion (C) and of patient 1 after 200 and $400 \mathrm{mg}$ i.v. infusions (D).

To investigate the toxicity-related aspect of HCQ regarding retinopathy, HCQ exposure was simulated in human eyes at 200,600 , and $1200 \mathrm{mg} / \mathrm{d}$ oral dosing and can be found in Supplemental Fig. 4. Single-dose HCQ at these levels generate relatively low concentrations in the eye relative to the other tissues shown in Supplemental Fig. 2, although eyes continue to retain HCQ as blood levels decline. After 30 days of once-daily dosing, it is clear that $1200 \mathrm{mg} / \mathrm{d}$ causes significantly higher accumulation of HCQ within the eyes, approximately 10 -fold more than $200 \mathrm{mg} / \mathrm{d}$. It is of note that even 2 months after dosing is discontinued the concentration of HCQ in the eyes decreases only slightly, indicating an extremely long $t_{1 / 2}$. Sixty days of once-daily dosing show a similar trend as 30 days, although concentration buildup begins to taper off. Concentrations in the human eyes at $1200 \mathrm{mg} / \mathrm{d}$ are close to those observed in the eyes of hooded rats dosed at $40 \mathrm{mg} / \mathrm{kg}$ for 6 days/wk over the same time frame (McChesney, 1983).

Simulated Steady-State Concentration and Clinical Trial Comparison. After the model was validated for singledose HCQ in human patients, the dosing interval was extended out to investigate predictive capability over a much longer period of time. Using generic human PBPK parameters as listed in Table 1, the model was used to simulate once-daily oral dosing of $100,200,400,600,800,1000$, and $1200 \mathrm{mg} \mathrm{HCQ}$ for a 30-day period. The steady-state concentration (Css) was taken as the average whole-blood concentration occurring after 20 days. Simulated Css for each dosing regimen was compared with the patient Css distribution of the corresponding dosing regimen in five different cancer clinical trials using HCQ in combination with another treatment in Fig. 6 (Mahalingam et al., 2014; Rangwala et al., 2014a,b; Rosenfeld et al., 2014; Vogl et al., 2014).
The trials reported reaching the concentration distribution depicted by the following days: temsirolimus at 15 days; vorinostat at 20 days; bortezomib at 21 days; temozolomide glioblastoma did "not distinctly represent steady state" and the time was not reported; and temozolomide solid tumor/melanoma at 16 days. The depicted range in all trials represents concentrations falling within the second and third quartile of patient data, except for vorinostat, which represents the mean \pm S.D. Of all trials examined, only the temozolomide glioblastoma patient population had a regression line statistically significant from the PBPK simulation. The regression line for this trial had a mean slope of 3.3 with $95 \%$ confidence interval bounds of $2.3-4.3$, compared with the regression line of the PBPK simulation that had a mean slope of 2.2. The vorinostat patient population did not undergo regression analysis due to only two daily doses of HCQ (400 and $600 \mathrm{mg}$ ) used in the trial, but the slope of this line was 1.7 compared with the PBPK simulation of 2.2. Of all trials tested against the PBPK simulation, average Css from the model human fell within the bounds of the second and third quartile for all dosing regimens except for the temozolomide glioblastoma $800 \mathrm{mg}$ and temsirolimus $400 \mathrm{mg}$.

Simulation of HCQ in a Virtual Population. Once model-simulated Css was found to be in good agreement with clinical trial Css distributions, the model was tested in a virtual population of humans. Two hundred and fifty males and 250 females were generated from the physiologic parameters for PBPK-modeling (P3M) database using PopGen (McNally et al., 2015). Briefly, P3M is a massive database of US patient records containing their associated physiologic data, and was developed by the Lifeline Group (Annandale, VA). Using PopGen to extract from this database, a virtual 

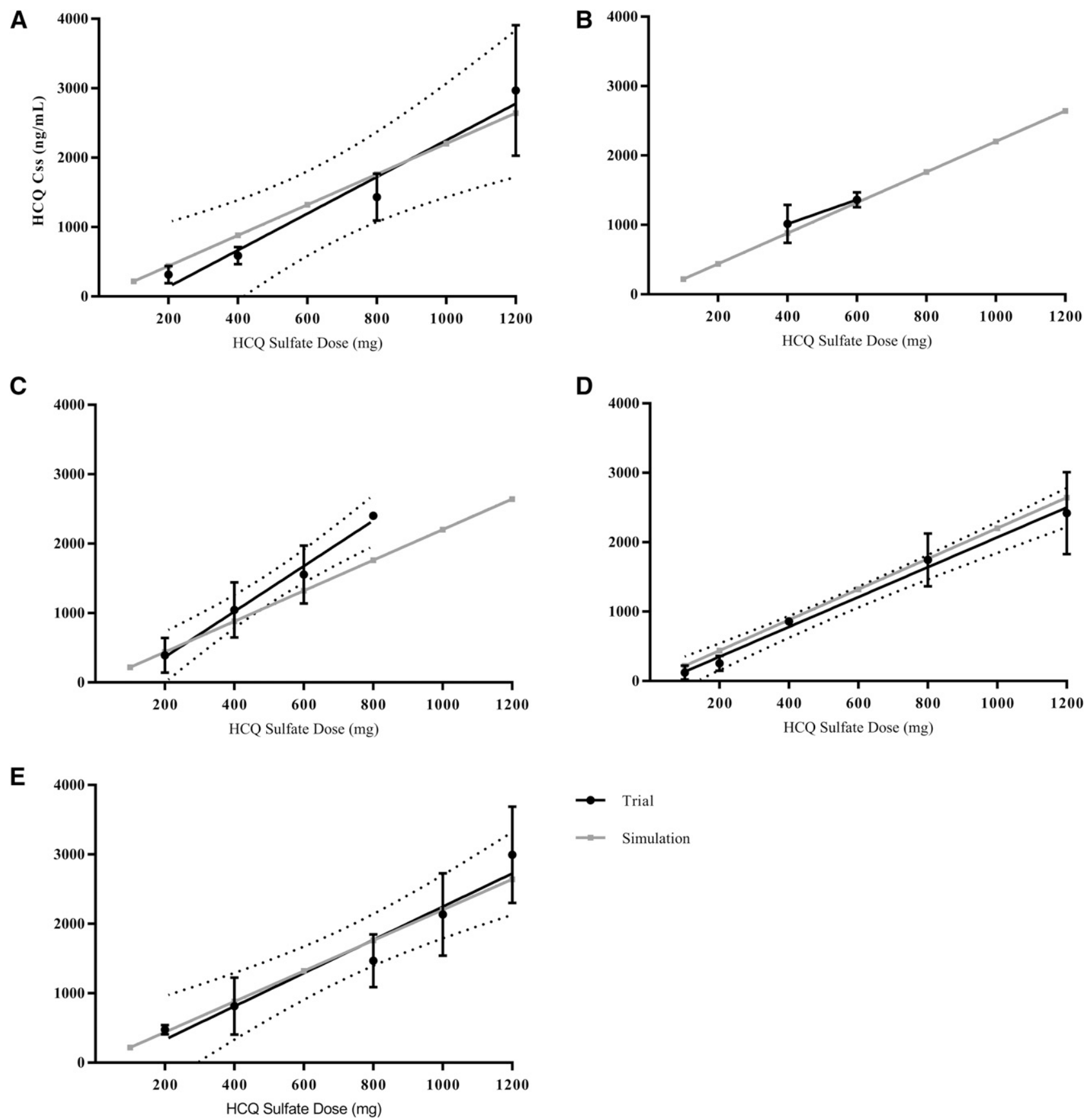

Fig. 6. Whole-blood concentrations of HCQ at steady state-comparison between five different human cancer clinical trials and PBPK model output at varying doses. The combination trials represented include (A) temsirolimus (Rangwala et al., 2014a), (B) vorinostat (Mahalingam et al., 2014), (C) temozolomide in glioblastoma patients (Rosenfeld et al., 2014), (D) bortezomib (Vogl et al., 2014), and (E) temozolomide in advanced solid tumor and melanoma patients (Rangwala et al., 2014b). Clinical trial data represent Css between the second and third quartile of patients, except for the vorinostat trial (B), which represents the mean \pm S.D. Css from the PBPK model were taken as the average concentration occurring at 20 days of once-daily oral dosing. Black lines represent the regression lines for clinical trial data; dotted black lines represent the $95 \%$ confidence interval; and gray lines represent the regression line for PBPK simulated data. The only trial that had a regression slope statistically different from the PBPK simulation was the temozolomide glioblastoma trial (C).

population of individuals was generated using available demographic data from the bortezomib/HCQ combination phase I clinical trial (Vogl et al., 2014). This was assumed to generate a population representative of a general cancer clinical trial. Css was then simulated for this population at each dosing regimen, and the simulated distribution was compared with the actual distribution observed in the clinical trials referenced. Each dose from 100 to $1200 \mathrm{mg}$ dosed once daily was simulated in each of the 500 total patients to generate a realistic range of Css. The results of this simulated patients compared with the actual distribution from each trial are shown in Fig. 7.

The model captured the distribution of whole-blood Css in the simulated patient population extremely well at low doses. The higher doses in the clinical trial population exhibited much more distributional variability between trials. This was 
A

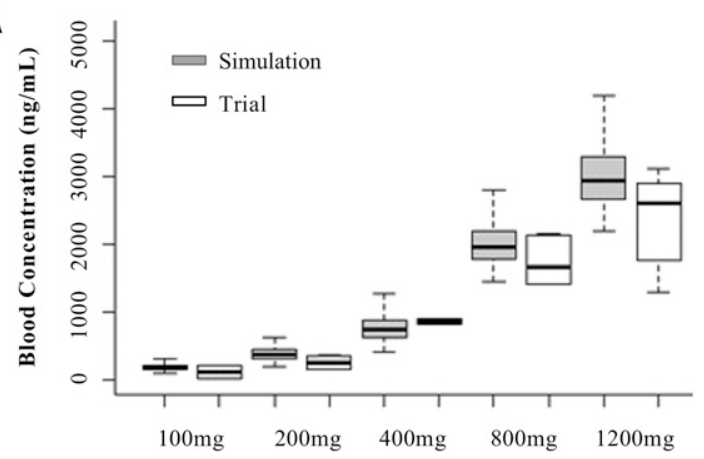

C

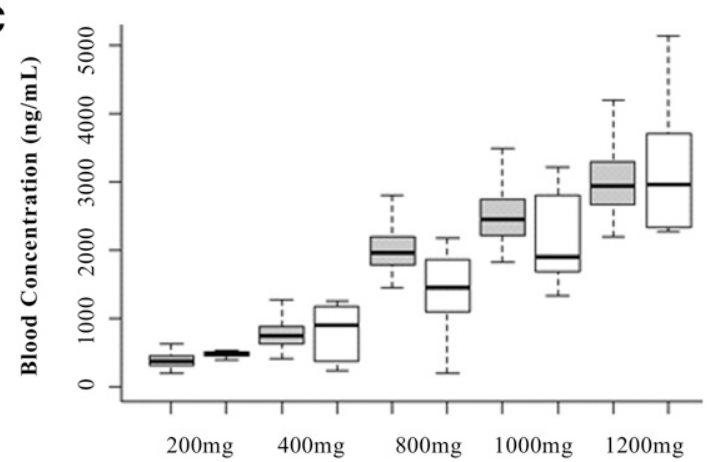

B

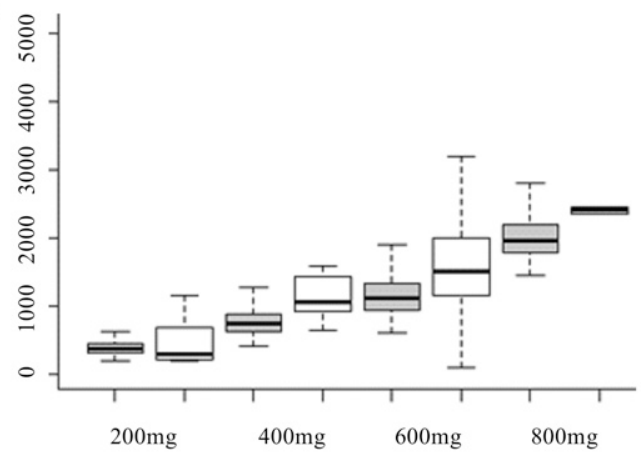

D

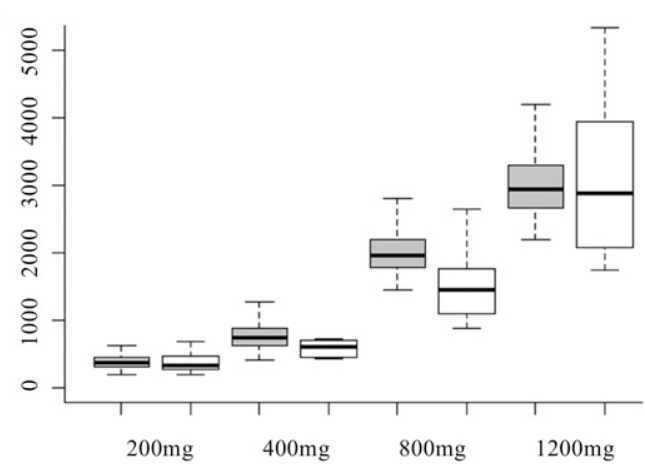

Fig. 7. Distribution of whole-blood Css (at 20 days) for patients in different dosing cohorts-a comparison of simulated data versus actual patient data from four clinical trials. Plots in gray represent the PBPK model simulation of HCQ in a virtual population of 500 patients (half male and half female) randomly generated using demographic data from the bortezomib trial. Plots in white represent the whole-blood HCQ concentration distribution for patients in one of the four clinical trials, including (A) bortezomib (Vogl et al., 2014), (B) temozolomide in glioblastoma patients (Rosenfeld et al., 2014), (C) temozolomide in patients with solid tumors or melanoma (Rangwala et al., 2014b), and (D) temsirolimus (Rangwala et al., 2014a). Virtual population was generated for 250 males and 250 females using the PopGen web software and pulling patient data from the P3M patient database.

expected due to the more prominent effect that variability in physiologic parameters will have at higher doses. Additionally, the clinical trial patient populations were relatively small, especially in comparison with the 500 virtual patients simulated by the model, which is another likely contributor to the distributional variability between trials.

\section{Discussion}

PBPK modeling is a relatively well-established concept, dating back to the first modern model of methotrexate in 1971 (Bischoff et al., 1971). Cancer therapy is a major field for development of these models due to the ability to simulate multiple dosing regimens in a relatively short period of time with the purpose of maintaining therapeutic efficacy while minimizing toxicity. This includes PBPK models for some drugs that have been used in clinical trials in combination with $\mathrm{HCQ}$, including three of those discussed in this work (Gustafson et al., 2002; Ballesta et al., 2014; Zhang and Mager, 2015). Although the utility of PBPK models appears increasingly clear, their use in a clinical setting is not well established. With treatment including, but not limited to malaria, lupus, rheumatoid arthritis, and now cancer, HCQ is a prime candidate for use of PBPK models in a personalized-medicine setting. Due to the widespread use of this drug, accounting for sources of PK variability from easily monitored driving parameters, such as gastrointestinal absorption, CYP3A4 and CYP2C3 metabolism, and renal clearance, could be a quick method of accounting for the broad range of patient PK profiles observed in a clinical setting. This would concurrently improve prediction of exposure in areas that are more difficult to monitor, such as melanin binding in the eye or variation in lysosomal content of a target site.

The described PBPK model for HCQ successfully predicts blood and tissue disposition in both mice and humans in single-dose oral, i.p., and i.v. scenarios. More so, it is capable of establishing a population distribution at doses ranging from 100 to $1200 \mathrm{mg}$ for long-term daily oral dosing in a human population representative of a general cancer clinical trial. This model was developed based on flow-limited uptake for the bulk compartments with perfusion-based uptake for the lysosomal compartment and accounts for specific binding to melanin and nonspecific binding to plasma protein. It is built based off physiologic and biochemically relevant parameters for eight compartments, three of which are validated by clinical PK data. These validated compartments consist of gut, liver, and kidney, along with whole blood. Gut and liver were included due to absorption and metabolism, respectively. Kidney is involved in renal clearance through filtration and secretion. There is evidence of reabsorption, but that mechanism was not considered in this model due to the lack of clinical data available relating urine $\mathrm{pH}$ to renal clearance of HCQ. Melanin binding was the primary reason for including eyes, specifically in regard to retinopathy observed in higher doses of HCQ used in cancer clinical trials. Accumulation of $\mathrm{HCQ}$ in the eyes was simulated to investigate the difference 
that dosing levels may have on retinal exposure to this drug. Although actual concentrations associated with retinopathy are unknown, patients classified as high risk are categorized as those receiving $>6.5 \mathrm{mg} / \mathrm{kg}$ per day for $>5$ years (Pandya et al., 2015). The model can be used to simulate and avoid HCQ retinal accumulation thresholds observed within these highrisk dosing levels. Heart was included due to rare incidence of irreversible cardiomyopathy that could possibly be exacerbated during long-term dosing of combination therapies that also exhibit some level of cardiovascular toxicity (Al-Bari, 2015). Treatments associated with cardiomyopathy are extremely rare, with only 42 known cases as of 2014 and reported mean cumulative doses of $1843 \mathrm{~g}$ (Yogasundaram et al., 2014). Remaining tissues were grouped into the rapidly perfused compartment, consisting of remaining viscera, and the slowly perfused compartment that consists of bone, muscle, and adipose.

The model was initially developed in mice and began with gathering of relevant biochemical and physiologic parameters. After this step, parameter effect on model fit to actual data was assessed. This was followed by optimization to maximize model accuracy across dosing regimens. Scaling to humans involved modifying relevant physiologic parameters and biochemical parameters, as seen in Table 1, and optimizing the model to fit human data. Validating against multiple types of human PK data offers the predictive power to simulate HCQ $\mathrm{PK}$ in patients while taking into account $\mathrm{PK}$ modification by combination treatment modalities, drug concentrations at the active site in the lysosome under varying $\mathrm{pH}$ conditions, and exposure in tissues where toxicity is observed. Interindividual variability in response is one of the primary concerns in treatments with HCQ. From a PK perspective, of all parameters the ones that the blood portion of the model are most dependent on are body weight, rate of metabolism, and blood partitioning and protein binding. Contribution of these factors to model performance is not dose dependent, i.e., linear with dose escalation. Patients with impaired liver or kidney function would likely be exposed to higher concentrations of HCQ, which would need to be accounted for in application of this model.

Primary value of this model is found through accurate simulation of HCQ PK in mice and humans while taking into account exposure in tissues, especially those where toxicity or clinical efficacy may be observed. Mice were the species chosen to begin model development due to the option of PK/PD investigation in whole organs. Between the mouse PK data, PD data (not yet published), and the likelihood that mice will be used in future preclinical studies with HCQ or nextgeneration analogs, this model will prove a valuable tool to make connections between exposure and response in a preclinical setting. This is especially relevant in the context of lysosomal uptake and the effect of these various factors on the PK/PD of HCQ and next-generation lysosomotropic autophagy inhibitors. Being a major driver of HCQ PK, it is important to note that lysosomes are a dynamic system undergoing effects such as swelling, biogenesis, $\mathrm{pH}$ modulation, and turnover that is not well characterized from a quantitative perspective in the presence of HCQ (Zhitomirsky and Assaraf, 2014; Lu et al., 2017). As pH is the driver for lysosomal accumulation, it plays an important role, especially in a tumor context where acidic conditions can dramatically affect HCQ uptake (Pellegrini et al., 2014; Zhitomirsky and Assaraf, 2015). The cellular model of lysosomal uptake applied in our PBPK model (Trapp and Horobin, 2005; Trapp et al., 2008; Kornhuber et al., 2010) serves as a strong base of modification to begin describing whole-tissue PK based on the pH-lysosome relationship. Further advancement of this PBPK model will require stronger prediction power in a tumor setting. Achieving this involves further characterization of these natural and HCQ-influenced lysosomal dynamics, and how they are related to intra- and extracellular $\mathrm{pH}$ in a tumor setting.

In addition to its use as a tool for further characterization of autophagy dependence and preclinical study, this model has proven its utility in predicting exposure in human patients as well. The model was validated in humans by accurately simulating blood exposure and urinary clearance of HCQ over a 72-hour period following oral and i.v. administration of two different doses. Additionally, it captured the distribution of Css at seven different dosing levels in a larger population of patients. Overall, it is able to simulate both early time points and steady-state values of patients at all concentrations used in a cancer clinical trial setting. This validation, in conjunction with the physiologic nature of the model, makes it a powerful tool in predicting patient exposure in the $50^{+}$clinical trials currently administering HCQ.

\section{Acknowledgments}

We thank Dr. Andrew Thorburn at the University of Colorado Anschutz Medical Campus for guidance with autophagy and hydroxychloroquine research, and also Dr. Stefan Trapp at the Technical University of Denmark for assistance with the lysosomal component of this model.

\section{Authorship Contributions}

Participated in research design: Collins, Jackson, Gustafson.

Conducted experiments: Collins, Jackson.

Contributed new reagents or analytic tools: Collins.

Performed data analysis: Collins.

Wrote or contributed to the writing of the manuscript: Collins, Gustafson.

\section{References}

Al-Bari MA (2015) Chloroquine analogues in drug discovery: new directions of uses, mechanisms of actions and toxic manifestations from malaria to multifarious diseases. J Antimicrob Chemother 70:1608-1621.

Amaravadi RK, Lippincott-Schwartz J, Yin XM, Weiss WA, Takebe N, Timmer W, DiPaola RS, Lotze MT, and White E (2011) Principles and current strategies for targeting autophagy for cancer treatment. Clin Cancer Res 17:654-666.

Ballesta A, Zhou Q, Zhang X, Lv H, and Gallo JM (2014) Multiscale design of celltype-specific pharmacokinetic/pharmacodynamic models for personalized medicine: application to temozolomide in brain tumors. CPT Pharmacometrics Syst Pharmacol 3:e112.

Barnard RA, Wittenburg LA, Amaravadi RK, Gustafson DL, Thorburn A, and Thamm DH (2014) Phase I clinical trial and pharmacodynamic evaluation of combination hydroxychloroquine and doxorubicin treatment in pet dogs treated for spontaneously occurring lymphoma. Autophagy 10:1415-1425.

Bischoff KB, Dedrick RL, Zaharko DS, and Longstreth JA (1971) Methotrexate pharmacokinetics. J Pharm Sci 60:1128-1133.

Brown RP, Delp MD, Lindstedt SL, Rhomberg LR, and Beliles RP (1997) Physiological parameter values for physiologically based pharmacokinetic models. Toxicol Ind Health 13:407-484.

Browning DJ (2014) Pharmacology of chloroquine and hydroxychloroquine, in Hydroxychloroquine and Chloroquine Retinopathy (Browning DJ ed) pp 35-63, Springer-Verlag, New York.

Carew JS, Kelly KR, and Nawrocki ST (2012) Autophagy as a target for cancer therapy: new developments. Cancer Manag Res 4:357-365.

Chiba M, Ishii Y, and Sugiyama Y (2009) Prediction of hepatic clearance in human from in vitro data for successful drug development. AAPS J 11:262-276.

Choi W, Baumann B, Liu JJ, Clermont AC, Feener EP, Duker JS, and Fujimoto JG (2012) Measurement of pulsatile total blood flow in the human and rat retina with ultrahigh speed spectral/Fourier domain OCT. Biomed Opt Express 3:1047-1061. de Duve C (1983) Lysosomes revisited. Eur J Biochem 137:391-397.

Durairaj C, Chastain JE, and Kompella UB (2012) Intraocular distribution of melanin in human, monkey, rabbit, minipig and dog eyes. Exp Eye Res 98:23-27. 
Fan HW, Ma ZX, Chen J, Yang XY, Cheng JL, and Li YB (2015) Pharmacokinetics and bioequivalence study of hydroxychloroquine sulfate tablets in Chinese healthy volunteers by LC-MS/MS. Rheumatol Ther 2:183-195.

Furst DE (1996) Pharmacokinetics of hydroxychloroquine and chloroquine during treatment of rheumatic diseases. Lupus 5 (Suppl 1):S11-S15.

Gustafson DL, Rastatter JC, Colombo T, and Long ME (2002) Doxorubicin pharmacokinetics: macromolecule binding, metabolism, and excretion in the context of a physiologic model. J Pharm Sci 91:1488-1501.

Ishizaki J, Yokogawa K, Ichimura F, and Ohkuma S (2000) Uptake of imipramine in rat liver lysosomes in vitro and its inhibition by basic drugs. J Pharmacol Exp Ther 294:1088-1098.

Kawashima A, Sato A, Kawashima M, Nitta K, Yumura W, Sugino N, Nihei H, and Natori Y (1998) A simple procedure for the isolation of rat kidney lysosomes. Kidney Int 54:275-278.

Kim KA, Park JY, Lee JS, and Lim S (2003) Cytochrome P450 2C8 and CYP3A4/5 are involved in chloroquine metabolism in human liver microsomes. Arch Pharm Res 26:631-637.

Kornhuber J, Henkel AW, Groemer TW, Städtler S, Welzel O, Tripal P, Rotter A, Bleich S, and Trapp S (2010) Lipophilic cationic drugs increase the permeability of lysosomal membranes in a cell culture system. J Cell Physiol 224:152-164.

Levy JM, Thompson JC, Griesinger AM, Amani V, Donson AM, Birks DK, Morgan MJ, Mirsky DM, Handler MH, Foreman NK, et al. (2014) Autophagy inhibition improves chemosensitivity in BRAF(V600E) brain tumors. Cancer Discov 4:773-780.

Levy JMM, Towers CG, and Thorburn A (2017) Targeting autophagy in cancer. Nat Rev Cancer 17:528-542.

Lim HS, Im JS, Cho JY, Bae KS, Klein TA, Yeom JS, Kim TS, Choi JS, Jang IJ, and Park JW (2009) Pharmacokinetics of hydroxychloroquine and its clinical implications in chemoprophylaxis against malaria caused by Plasmodium vivax. Antimicrob Agents Chemother 53:1468-1475.

Lu S, Sung T, Lin N, Abraham RT, and Jessen BA (2017a) Lysosomal adaptation: how cells respond to lysosomotropic compounds. PLoS One 12:e173771.

$\mathrm{Lu} \mathrm{ZN}$, Tian B, and Guo XL (2017b) Repositioning of proton pump inhibitors in cancer therapy. Cancer Chemother Pharmacol 80:925-937.

Mahalingam D, Mita M, Sarantopoulos J, Wood L, Amaravadi RK, Davis LE, Mita AC, Curiel TJ, Espitia CM, Nawrocki ST, et al. (2014) Combined autophagy and HDAC inhibition: a phase I safety, tolerability, pharmacokinetic, and pharmacodynamic analysis of hydroxychloroquine in combination with the HDAC inhibitor vorinostat in patients with advanced solid tumors. Autophagy 10:1403-1414.

McChesney EW (1983) Animal toxicity and pharmacokinetics of hydroxychloroquine sulfate. Am J Med 75:11-18.

McChesney EW, Banks WF, Jr, and Fabian RJ (1967) Tissue distribution of chloroquine, hydroxychloroquine, and desethylchloroquine in the rat. Toxicol Appl Pharmacol 10:501-513.

McChesney EW, Conway WD, Banks WF, Jr, Rogers JE, and Shekosky JM (1966) Studies of the metabolism of some compounds of the 4-amino-7-chloroquinoline series. J Pharmacol Exp Ther 151:482-493.

McNally K, Cotton R, Hogg A, and Loizou G (2015) Reprint of PopGen: a virtual human population generator. Toxicology 332:77-93.

Meijer DK and van der Sluijs P (1989) Covalent and noncovalent protein binding of drugs: implications for hepatic clearance, storage, and cell-specific drug delivery. Pharm Res 6:105-118.

Ohkuma S and Poole B (1978) Fluorescence probe measurement of the intralysosomal $\mathrm{pH}$ in living cells and the perturbation of $\mathrm{pH}$ by various agents. Proc Natl Acad Sci USA 75:3327-3331.

Pandya HK, Robinson M, Mandal N, and Shah VA (2015) Hydroxychloroquine retinopathy: a review of imaging. Indian J Ophthalmol 63:570-574.

Pellegrini P, Strambi A, Zipoli C, Hägg-Olofsson M, Buoncervello M, Linder S, and De Milito A (2014) Acidic extracellular pH neutralizes the autophagy-inhibiting activity of chloroquine: implications for cancer therapies. Autophagy 10:562-571.

Qi Z and Breyer MD (2009) Measurement of glomerular filtration rate in conscious mice. Methods Mol Biol 466:61-72.

Qu Y, Noe G, Breaud AR, Vidal M, Clarke WA, Zahr N, Dervieux T, CostedoatChalumeau N, and Blanchet B (2015) Development and validation of a clinical HPLC method for the quantification of hydroxychloroquine and its metabolites in whole blood. Future Sci OA 1:FSO26.

Rangwala R, Chang YC, Hu J, Algazy KM, Evans TL, Fecher LA, Schuchter LM, Torigian DA, Panosian JT, Troxel AB, et al. (2014a) Combined MTOR and autophagy inhibition: phase I trial of hydroxychloroquine and temsirolimus in patients with advanced solid tumors and melanoma. Autophagy 10:1391-1402.

Rangwala R, Leone R, Chang YC, Fecher LA, Schuchter LM, Kramer A, Tan KS, Heitjan DF, Rodgers G, Gallagher M, et al. (2014b) Phase I trial of hydroxychloroquine with dose-intense temozolomide in patients with advanced solid tumors and melanoma. Autophagy 10:1369-1379.

Rosenfeld MR, Ye X, Supko JG, Desideri S, Grossman SA, Brem S, Mikkelson T, Wang D, Chang YC, Hu J, et al. (2014) A phase I/II trial of hydroxychloroquine in conjunction with radiation therapy and concurrent and adjuvant temozolomide in patients with newly diagnosed glioblastoma multiforme. Autophagy 10: 1359-1368.

Schroeder RL and Gerber JP (2014) Chloroquine and hydroxychloroquine binding to melanin: some possible consequences for pathologies. Toxicol Rep 1:963-968.

Sewell RB, Dillon C, Grinpukel S, Yeomans ND, and Smallwood RA (1986) Pericanalicular location of hepatocyte lysosomes and effects of fasting: a morphometric analysis. Hepatology 6:305-311.

Sheiner LB and Beal SL (1981) Some suggestions for measuring predictive performance. J Pharmacokinet Biopharm 9:503-512.

Shi TT, Yu XX, Yan LJ, and Xiao HT (2017) Research progress of hydroxychloroquine and autophagy inhibitors on cancer. Cancer Chemother Pharmacol 79:287-294.

Tett S, Cutler D, and Day R (1990) Antimalarials in rheumatic diseases. Baillieres Clin Rheumatol 4:467-489.

Tett SE, Cutler DJ, Day RO, and Brown KF (1988) A dose-ranging study of the pharmacokinetics of hydroxy-chloroquine following intravenous administration to healthy volunteers. Br J Clin Pharmacol 26:303-313.

Tett SE, Cutler DJ, Day RO, and Brown KF (1989) Bioavailability of hydroxychloroquine tablets in healthy volunteers. Br J Clin Pharmacol 27:771-779.

Thelen K and Dressman JB (2009) Cytochrome P450-mediated metabolism in the human gut wall. J Pharm Pharmacol 61:541-558.

Trapp S and Horobin RW (2005) A predictive model for the selective accumulation of chemicals in tumor cells. Eur Biophys J 34:959-966.

Trapp S, Rosania GR, Horobin RW, and Kornhuber J (2008) Quantitative modeling of selective lysosomal targeting for drug design. Eur Biophys $J$ 37:1317-1328.

Vogl DT, Stadtmauer EA, Tan KS, Heitjan DF, Davis LE, Pontiggia L, Rangwala R, Piao S, Chang YC, Scott EC, et al. (2014) Combined autophagy and proteasome inhibition: a phase 1 trial of hydroxychloroquine and bortezomib in patients with relapsed/refractory myeloma. Autophagy 10:1380-1390.

Warhurst DC, Steele JC, Adagu IS, Craig JC, and Cullander C (2003) Hydroxychloroquine is much less active than chloroquine against chloroquine-resistant Plasmodium falciparum, in agreement with its physicochemical properties. $J$ Antimicrob Chemother 52:188-193.

Wei Y, Nygard GA, Ellertson SL, and Khalil SK (1995) Stereoselective disposition of hydroxychloroquine and its metabolite in rats. Chirality 7:598-604.

Yang ZJ, Chee CE, Huang S, and Sinicrope FA (2011) The role of autophagy in cancer: therapeutic implications. Mol Cancer Ther 10:1533-1541.

Yogasundaram H, Putko BN, Tien J, Paterson DI, Cujec B, Ringrose J, and Oudit GY (2014) Hydroxychloroquine-induced cardiomyopathy: case report, pathophysiology, diagnosis, and treatment. Can J Cardiol 30:1706-1715.

Zhang L and Mager DE (2015) Physiologically-based pharmacokinetic modeling of target-mediated drug disposition of bortezomib in mice. J Pharmacokinet Pharmacodyn 42:541-552.

Zhi Z, Yin X, Dziennis S, Wietecha T, Hudkins KL, Alpers CE, and Wang RK (2012) Optical microangiography of retina and choroid and measurement of total retinal blood flow in mice. Biomed Opt Express 3:2976-2986.

Zhitomirsky B and Assaraf YG (2014) Lysosomal sequestration of hydrophobic weak base chemotherapeutics triggers lysosomal biogenesis and lysosome-dependent cancer multidrug resistance. Oncotarget 6:1143-1156.

Zhitomirsky B and Assaraf YG (2015) The role of cytoplasmic-to-lysosomal pH gradient in hydrophobic weak base drug sequestration in lysosomes. Cancer Cell Microenviron 2:e807.

Address correspondence to: Dr. Daniel L. Gustafson, FACC246, Flint Animal Cancer Center, Colorado State University Veterinary Teaching Hospital, 300 West Drake Road, Fort Collins, CO 80523. E-mail: Daniel. Gustafson@ColoState.edu 